Transportation Research Forum

Comparing Approaches to Winter Highway Maintenance Operations Through User Mobility

Performance

Author(s): Jean-Claude Thill and Hai Sun

Source: Journal of the Transportation Research Forum, Vol. 48, No. 1 (Spring 2009), pp. 49-64

Published by: Transportation Research Forum

Stable URL: http://www.trforum.org/journal

The Transportation Research Forum, founded in 1958, is an independent, nonprofit organization of transportation professionals who conduct, use, and benefit from research. Its purpose is to provide an impartial meeting ground for carriers, shippers, government officials, consultants, university researchers, suppliers, and others seeking exchange of information and ideas related to both passenger and freight transportation. More information on the Transportation Research Forum can be found on the Web at www.trforum.org. 


\title{
Comparing Approaches to Winter Highway Maintenance Operations Through User Mobility Performance
}

\author{
by Jean-Claude Thill and Hai Sun
}

This paper compares the winter maintenance performances of sections of two limited access highways operated by the New York State Department of Transportation (NYSDOT) and the New York State Thruway Authority (NYSTA). Performance is assessed by two user mobility indicators: speed reduction during snowstorms and speed recovery duration following the end of snow events. Multivariate linear regressions are estimated to model these mobility indicators. The results show major discrepancies in level of service between the two agencies, particularly in the early stages of snowstorms. Another result is that speed recovery is indistinguishable in the hour following the end of snow events. It also found that NYSTA's higher outlay of resources appears to be effective only during short storms and in the early stages of storms.

\section{INTRODUCTION}

Weather conditions can have extremely adverse impacts on highway mobility and traveler safety in many high-latitude regions of the United States. Therefore, effective snow removal and ice control are essential road services for highway users during the winter season. In the Buffalo, NY, metropolitan area, the ground is often snow-covered through the winter months, particularly from mid-December through early March. Over half of the annual snowfall comes from the "lake-effect" process and is rather localized according to a pattern of east-west bands. Lake-effect snow develops when eastward cold air masses cross the relatively warm waters of Lake Erie, become saturated, and produce orographic precipitation downwind (Niziol et al. 1995). The average annual accumulated snow depth in the Buffalo metropolitan area is about 100 inches (NWS 2004), with a maximum of up to 200 inches.

The controlled access highway network of the Buffalo Metropolitan Area consists of two parts maintained by the New York State Department of Transportation (NYSDOT) and the New York State Thruway Authority (NYSTA). These agencies have differing standards of response for snow and ice control activities for the same classification of facilities. NYSTA standards call for more resources than the NYSDOT standards, so the NYSTA is often perceived to have a better level of service (LOS) during winter storm events and afterwards. The purpose of this study is to determine if LOS discrepancies between NYSDOT and NYSTA facilities can be detected during and after winter snow events, which could then be imputed to differences in snow and ice control standards. Based on aggregate travel time data estimated by Automatic Vehicle Identification (AVI) technology, this paper describes the analysis of two aspects of mobility and LOS, namely the speed reduction rate during snowstorm events and the time taken for speed recovery after storm events.

The rest of this paper is organized as follows. Salient literature on the effects of winter storms on traffic conditions and on winter maintenance performance measurement is first reviewed. In the next section, the research methodology is introduced. The collection and processing of data used are presented next, followed by the results of the econometric analysis of during- and afterstorm maintenance performance on selected segments of the Buffalo system of controlled access highways. Conclusions and recommendations are made in the closing section of the paper. 


\section{Winter Storms and Their Traffic Impacts}

Studies of the impact of wintry weather conditions on multiple characteristics of traffic can be traced back more than 30 years. Roadway capacity, traffic volume, and speed, as well as safety, are typically studied. Early research on adverse weather focused on highway capacity (e.g., Ries 1981; Hall and Barrow 1988). Hanbali and Kuemmel (1993) estimated the reduction in traffic volume under winter storm conditions for different control variables. It was found that reductions ranged from $7 \%$ to $56 \%$, depending on the category of winter event. Other studies on traffic volume impacts of wintry weather conditions are reported by McBride (1978), Perry and Symons (1991), Nixon (1998), Botha and Kruse (1992), and Knapp et al. (2000a), while the safety consequences of wintry conditions have been studied by Hanbali (1994), Brown and Baass (1997), Knapp et al. (2000a), and others.

Snow precipitation and accumulation on pavement render driving conditions hazardous. Drivers react to the snow by slowing down. McBride (1978) inferred from data collected in Utah, Idaho, Minnesota, and Illinois that the average free flow speed drops 13\% on limited-access highways whose pavement is wet or snow-covered; it falls $22 \%$ when the pavement is wet or slushy. If nothing was done to the roadway and the snow started sticking and was packed, average speed was reduced from $30 \%$ to $42 \%$. Ibrahim and Hall (1994) studied the effect of adverse weather on freeway operations in Canada. They conducted tests on the effects of rain and snow on speed-flowoccupancy relationships and found that light snow caused a three kilometers per hour drop in freeflow speed while heavy snow caused a considerably larger drop, namely 38 to 50 kilometers per hour. Padget et al. (2001) found that winter weather conditions in Iowa lower daytime speed by 11.9 miles per hour on average, against 10.2 miles per hour during the night. Significant differences in speeds were also found for passenger cars, pickup trucks, and sport utility vehicles.

Liang et al. (1998) investigated the effects of snow and fog on driver speed during the 1995-1996 winter based on data collected by a storm warning system located near Shoshone, ID, adjacent to Interstate 84 (I84). The authors found a 19.2 kilometers per hour speed reduction during snow events. This study considered the effects of several environmental factors such as visibility reductions, precipitation levels, and wind speeds. Several speed-related effects were identified through multivariate regression modeling. First, it found a reduction in driver speed of 1.1 kilometers per hour for every unit increase of wind speed above 40 kilometers per hour. Also, drivers reduced their speed by 1.6 kilometers per hour at night, and the presence of snow cover on pavements reduced average speed by 5.6 kilometers per hour.

Using data from the same source as Liang et al. (1998) during the winters of 1997-1998 and 1998-1999, Kyte et al. (2001) found that the presence of ice or snow on the pavement causes drivers to dramatically reduce their speeds. The results also indicated that the intensity of snow precipitation had a significant effect on vehicle speed. Stern et al. (2003) examined weather impacts on 33 road segments in metropolitan Washington, D.C., from December 1999 to May 2001. Reported travel time data and weather observation data were combined and used in a two-step regression analysis to predict travel time impacts under adverse weather conditions. The average increase in arterial travel time was over $12 \%$ when adverse weather occurred during a two-hour off-peak period. The predicted increase in arterial travel time exceeded $48 \%$ during snowstorm events. Knapp et al. (2000b) and Knapp and Smithson (2000) examined data from 64 snow events in Iowa and concluded that vehicle speed fell 16\% during snow events, compared to baseline conditions.

\section{Winter Maintenance Performance Measurement}

Performance measurement during winter aims at evaluating the effectiveness and efficiency of roadway snow and ice control strategies for specific weather and traffic conditions. A recent NCHRP 
report by Blackburn et al. (2004) underscores the importance of proper performance measures in implementing snow and ice control systems. Decker et al. (2004) formulated a winter maintenance efficiency metric as the daily snow-fighting expenditure normalized by the storm's severity index and lane mileage. This index is an input-based approach instead of an outcome measure since it does not take into account the resulting effectiveness of winter maintenance operations on road users. In the same vein, Adams et al. (2003) described a comprehensive set of resource-oriented performance measures implemented in the state of Wisconsin for analyzing winter road maintenance level of service policies for evaluating the performance of materials, labor, and equipment used in snow and ice control operations, and for developing reliable evidence of compliance with standards and policies. On the other hand, Vaa (2001) took an outcome perspective in his work for Norway's Winter Friction Project. He measured the pavement friction improvement to evaluate the effectiveness of snow and ice control actions. Along with the friction measurement, pictures were taken so that the road surface could be categorized with greater accuracy.

In their research on the level of snow removal and ice control management in Japan, Yamada et al. (2004) found that the amount of snow cover on pavements was a key factor affecting vehicle speed. They suggested that vehicle speed was an appropriate index of the level of road management in regions experiencing heavy snow falls. The same performance measure has been suggested by many other researchers, including Knapp et al. (2000b), Knapp and Smithson (2000), and Kyle et al. (2001).

Lee and Ran (2004), using data collected at Wisconsin DOT's automatic traffic recorder sites in the 2002-2003 winter season, developed a method for measuring the performance of winter road maintenance. Instead of tallying the total costs of operations or supplies, they proposed measuring the elapsed time between the end of a snow event and the time when traffic speed returned to normal, which they termed the speed-recovery duration. Their multivariate regression analysis identified two variables to be significantly associated with speed recovery duration, namely the maximum speed reduction during a snow event and the duration of the snow event itself.

\section{METHODOLOGY}

In this study, the goal is to determine whether the adoption of different snow and ice control standards by NYSDOT and NYSTA results in a discrepancy in user mobility performance of the facilities operated by the two agencies. The literature review has identified several possible measures of performance. Two mobility performance measures of winter maintenance are used in a complementary fashion in this study. The first measures performance during the snow event through the reduction in traffic speed in comparison to snow-free conditions. According to this measure, a facility performs better when the loss of speed is low during a snow event. Speed reduction during a snow event is calculated by subtracting the current travel speed from a baseline average speed developed for inclement weather conditions. The result then is divided by the baseline speed to produce a speed reduction rate expressed as a percentage, which will be the dependent variable in the during-storm performance model. Hence, the speed reduction rate (SRR) during a certain onehour period is $\left(1-\mathrm{S}_{\mathrm{o}} / \mathrm{S}_{\mathrm{b}}\right) * 100$, where $\mathrm{S}_{\mathrm{o}}$ is the observed average speed during the storm hour and $\mathrm{S}_{\mathrm{b}}$ is the baseline average traffic speed.

In addition to evaluating mobility performance during snow storms, it is also evaluated for the time period following the end of a snow event, as traffic is known to be disrupted for some time after snow precipitation has ceased. Three alternative indices of after-storm performance based on the speed recovery duration are defined for the purpose of this second analysis. The indices are:

- Speed Recovery Duration 1 (SRD1): The time that has lapsed from the end of a snow event to the moment when traffic flow returns to baseline speed;

- Speed Recovery Duration 2 (SRD2): The time from the end of a snow event to the moment when traffic flow returns to $95 \%$ of baseline speed;

- The average of SRD1 and SRD2: (AVGSRD). 
The SRD1 measure assumes a rather strict definition of the concept of speed recovery, which leaves no room for measurement errors or imprecision. The second measure is designed to allow for a 5\% tolerance in this respect. Finally, the last measure is a compromise between the first two.

Together, the speed reduction rate (SRR) and speed recovery duration measures (SRD1, SRD2) capture the effects of snow events during and after the event and enable us to assess the performance of ice and snow control measures against a benchmark of snow-free traffic conditions. Multivariate ordinary least squares (OLS) linear regression is used to model the performance of winter maintenance operations on traffic level of service during snowstorms as well as in their aftermath. In the model of during-storm maintenance performance, SRR is the dependent variable and is a function of traffic and weather conditions, jurisdiction, and directionality. Data records in the sample are hourly observations compiled on targeted highway segments during an entire winter season.

Three models of after-storm performance are estimated with SRD1, SRD2, and AVGSRD as the dependent variables, with traffic and weather conditions, jurisdiction, and directionality as the independent variables. The traffic and weather conditions used in the during-storm performance and the after-storm performance models are described later. The regression models also include binary variables for the direction of traffic flow on the targeted highway segments and the agency in charge of maintenance of each highway segment. The sample consists of all snow events that have affected the targeted highway segments during an entire winter season.

Each of the two modeling efforts is implemented as follows. First, models with traffic and weather conditions only are estimated based on a forward selection stepwise regression method with a probability of 0.05 for entry and 0.1 for removal. Residual scatter plots are then analyzed to ascertain compliance with the basic assumptions of regression analysis, particularly normality and homoscedasticity. In the second step, instrumental variables showing the direction of traffic flow and jurisdiction are added to the models.

\section{DATA COLLECTION AND MANIPULATION}

Consultation with engineers at the Niagara International Transportation Technology Coalition (NITTEC), NYSDOT, and NYSTA led to the selection of one section of Interstate 90 (I90) between mileposts 420.70 and 425.97 maintained by NYSTA, and another section of Interstate 290 (I290) between mileposts 5.84 and 9.80 maintained by NYSDOT for study. These sections are respectively 5.27 miles and 3.96 miles long (Figure 1). Several considerations were factored into making this choice. Most importantly, they are directly connected and have similar traffic composition, geometric characteristics, and pavement conditions. Additionally, they are equipped with the Intelligent Transportation System (ITS) technology that can be used to collect the necessary traffic data. Specifically, both selected segments are covered by TRANSCOM's System for Managing Incidents and Traffic (TRANSMIT), which provides real time and historical travel time information at a fine spatial-temporal resolution. Finally, the amount of snowfall on both highway segments was obtained from the National Weather Service (NWS)'s Next Generation Radar (NEXRAD) system located at the nearby Buffalo Niagara International Airport. Hence, it is possible to estimate the amount of snowfall on the two segments using the same equipment.

\section{NEXRAD Precipitation Data}

NEXRAD is a joint effort of the U.S. Departments of Commerce, Defense, and Transportation to develop, produce, deploy, and support the advanced Weather Surveillance Radar - 1988 Doppler (WSD-88D) System, that meets the common operational needs of the three agencies (Crum and Alberty 1993). WSD-88D obtains weather information (precipitation and wind) based upon returned energy. It provides highly sensitive fine-resolution meteorological measurements of reflectivity, mean radial velocity, and spectrum width, and generates up to 39 categories of analysis products 
Figure 1: Study Area

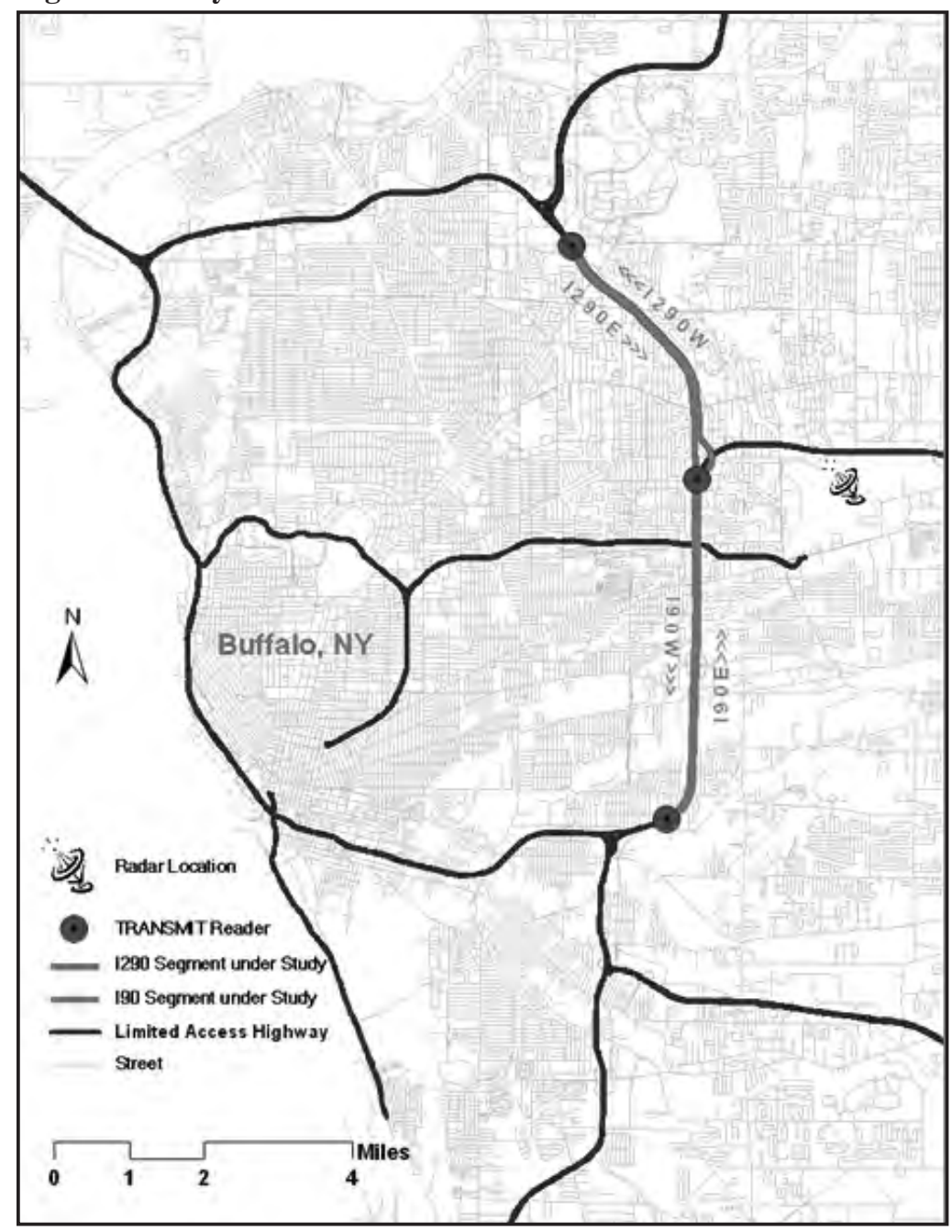

derived from the base data every five to 10 minutes (Klazura and Imy 1993). ${ }^{1}$ The radar data expressed in liquid water equivalent amount of solid precipitation per clock hour can be downloaded at the National Climate Data Center's website (NCDC 2008). ${ }^{2}$

The study area for this research is about two kilometers away from the Buffalo NEXRAD site and affords us a high spatial resolution of weather data in the order of two kilometers by 0.3 kilometer (Fulton 1998). For our purposes, polygon-based NEXRAD data are converted to pointbased records. The characteristics of these NEXRAD sample points are used to estimate average snow precipitation on the highway segments under study. The prevailing wind direction during the winter is from west to east in western New York, and precipitation is fairly uniform along this direction. Therefore, precipitation on the I290 and I90 highway segments is estimated on the basis of the two sets of NEXRAD sample points that fully cover the highway segments once projected east to west. Radar readings are averaged to produce a single precipitation estimate for each segment so as to derive a single hourly precipitation value for each segment.

Clock-hour precipitation and storm total precipitation of WSR-88D Stage I, Level-III NEXRAD Radar data are used to estimate hourly snow precipitation and storm accumulation from the start of a snow event (rounded off to the closest clock hour) to the current hour. ${ }^{3}$ A snow event extends over 
an integer number of clock hours and it is preceded and followed by at least one hour free of snow precipitation. These snow-free breaks separate snow events. Therefore, the clock hour immediately after the last one-hour break in snow precipitation is taken as the first hour of the storm and the clock hour immediately before the next one-hour break is the last hour of the storm.

\section{TRANSMIT Traffic Data}

TRANSMIT was developed to establish the feasibility of using Automatic Vehicle Identification (AVI) equipment for traffic management and surveillance applications (Niver et al. 2000). AVI technology systems are typically installed at toll booths where they classify oncoming vehicles, then identify and debit them by reading data stored on a vehicle-mounted transponder through wireless communication with a roadside antenna. This technology offers the potential for using vehicles equipped with transponders to serve as vehicle probes within the traffic stream of the area for which surveillance is being established. TRANSMIT requires roadside readers with the capability of identifying vehicles equipped with transponders for data collection purpose. The readers receive the identification numbers of transponder-equipped vehicles and record the number and the times of arrival of the vehicles. The transponder numbers and arrival times received by multiple roadside readers are transmitted by a central information processing center where travel time and average speed between readers are derived.

Due to its capability to capture real-time travel time, AVI technology is regarded as a cornerstone of Advanced Traffic Management Systems (ATMS) because travel time over a given section of a roadway is a much more meaningful control variable than point speed (Marshall 1997). Furthermore, as the proportion of vehicle probes in Buffalo's traffic stream ranges from $20 \%$ to $30 \%$ (Sun and Thill 2006), TRANSMIT-based speeds are good estimates of actual traffic speeds (Niver et al. 2000). For the purpose of this study, it is assumed that travel time variation (to be converted to speed) is a robust index of performance of winter maintenance operations.

To build a solid baseline to which performance during snow events can be compared, traffic data between December 15, 2004, and March 31, 2005, were gathered. All the clock hours with special events, snow events, or accidents were removed from the dataset. Then hourly traffic data were aggregated by averaging on the basis of clock hour and day of the week. This process produced a baseline average speed and a traffic volume for each hour of each day of a typical week.

Traffic volume and average speed for each segment (i.e., between two consecutive reader stations) and for each 15 minutes were downloaded from the TRANSMIT terminal at the NITTEC facility in Buffalo, NY. This data was aggregated to one-hour periods to maintain consistency across data used in the analysis. Once matched with hourly NEXRAD precipitation data, hourly records with no snowfall are discarded. Records with accidents in the current or previous hour were also removed and the hourly speed reduction rate (SRR) was calculated.

\section{Accident Data}

Accident data were obtained from the two law enforcement agencies with responsibilities over the expressway segments under study, namely the police department of the town of Amherst, NY, and the New York State Police. ${ }^{4}$ The accident information serves as one of the criteria to clean the data used in the maintenance performance models. All hourly traffic data coinciding with accidents in the current or preceding hour are removed.

\section{Variables Involved in Modeling During-Storm Performance}

The model of during-storm performance uses the speed reduction rate defined earlier as a measure of performance and the dependent variable, and the traffic characteristics and weather descriptors in Table 1 as the independent variables. Similar to the dependent variable, the first two independent 
variables are extracted from the TRANSMIT data source. These are control variables given the parabolic relationship known to exist between traffic volume and speed. The volume ratio variable accounts for any anticipation of inclement weather conditions on the part of motorists by foregoing vehicular travel altogether, thus reducing traffic volume. The remaining variables are weather conditions calculated from the NEXRAD data that may affect the current hour's travel speed. Some variables such as precipitation capture the severity of weather conditions during the current period, while others serve to characterize weather conditions earlier in the storm. Although other control variables such as visibility, road surface friction, and wind speed also affect traffic speed, they were not available for this research. Storm intensity accounts for the effect of anticipation of inclement weather conditions. Aside from these variables, the indicators I90E, I90W, I290E, and I20W identify the direction of traffic flow on the highway segments.

The dataset comprises 629 hourly data records with no missing values. Each record corresponds to a one-hour time interval on a highway segment. There are 182 records for 190 eastbound (I90E), 182 for 190 westbound (I90W), 132 for I290 westbound (I290W), and 133 for I290 eastbound (I290E). Thus, there are more data records for the I90 segments than for the I290 segments. This is because the 190 segments experienced longer hours of snow precipitation.

\section{Variables Involved in Modeling After-Storm Speed Recovery}

As indicated in the methodology section, the model of after-storm performance uses three different measures of speed recovery duration as measures of performance, namely SRD1, SRD2, and AVGSRD. The traffic characteristics and weather descriptors listed in the lower part of Table 1 are used as independent variables. Lee and Ran (2004) recently showed that maximum speed reduction and snow event duration are significant predictors of speed recovery duration. It is hypothesized here that other aspects of storm severity and their traffic consequences are significantly related to the time elapsed until traffic speed recovery. Again, the three indicators, I290E, I90E, I90W, are employed in the analysis to identify facility-specific effects. The dataset includes 60 data records from 31 different snow events: 18 records are for 190 eastbound, 18 for I90 westbound, 11 for I290 westbound, and 13 for I290 eastbound.

Tables 2 and 3 provide descriptive statistics for the data including the four subsets of segments of the roads. ${ }^{5}$ Table 2 shows that the mean speed reduction rates on 190 are about $10 \%$ and lower than the $15 \%$ on I290. These rates are similar to those reported by McBride (1978), Ibrahim and Hall (1994), Knapp et al. (2000b), and Knapp and Smithson (2000). However, speed reduction rates on all four segments have high standard deviation compared to their mean, showing that some extreme data exist. Table 3 shows the descriptive statistics of data used for modeling after-storm speed recovery. From this table, complete speed recovery occurs within 5.7 to 10.7 hours on average, while $95 \%$ speed recovery occurs within 1.2 to 2.6 hours on the average. 
Winter Highway Maintenance Operations

Table 1: Independent Variables

\section{Independent Variables in the M odel of During-storm Performance}

\begin{tabular}{|c|c|c|}
\hline Variable & Abbreviation & Definition \\
\hline Volume & V & Traffic volume in current clock hour \\
\hline Volume Ratio & VR & $\begin{array}{l}\text { Current traffic volume divided by baseline volume on the same } \\
\text { hour and week day }\end{array}$ \\
\hline Precipitation & $P$ & $\begin{array}{l}\text { A mount of snow precipitation in the current hour (liquid water } \\
\text { equivalent inches) }\end{array}$ \\
\hline Accumulation & A & $\begin{array}{l}\text { Cumulative amount of snowfall since the start of the storm event } \\
\text { up to the current clock hour (liquid water equival ent inches) }\end{array}$ \\
\hline N th Hour & $\mathrm{NH}$ & $\begin{array}{l}\text { Storm duration from the beginning, including the current hour } \\
\text { (hours) }\end{array}$ \\
\hline Past Intensity & $\mathrm{PI}$ & Past storm intensity (A ccumulation/(nthhour-1)) \\
\hline Storm Duration & SD & Total storm duration (hours) \\
\hline Storm Intensity & $\mathrm{SI}$ & $\begin{array}{l}\text { intensity (Average hourly snow precipitation throughout the } \\
\text { storm) (inches/hour) }\end{array}$ \\
\hline Precip(N-1) & PN1 & $\begin{array}{l}\text { Previous hour's precipitation ((n-1)th). When the data record is } \\
\text { relative to the first hour of a snow event, this variable is set to } \\
\text { zero }\end{array}$ \\
\hline Precip(N-2) & PN2 & $\begin{array}{l}\text { Precipitation in ( } n-2) \text { th hour. When the data record is relative to } \\
\text { the second hour of a snow event, this variable is set to zero }\end{array}$ \\
\hline Precip(N-3) & PN3 & $\begin{array}{l}\text { Precipitation in }(n-3) \text { th hour. W hen the data record is relative to } \\
\text { the third hour of a snow event, this variable is set to zero }\end{array}$ \\
\hline Precip(N-4) & PN 4 & $\begin{array}{l}\text { Precipitation in }(n-4) \text { th hour. W hen the data record is relative to } \\
\text { the fourth hour of a snow event, this variable is set to zero }\end{array}$ \\
\hline I90E & I90E & $\begin{array}{l}\text { B inary variable that is valued ' } 1 \text { ' is a record is on I90E, ' } 0 \text { ' } \\
\text { otherwise }\end{array}$ \\
\hline I90W & I90W & $\begin{array}{l}\text { B inary variable that is valued ' } 1 \text { ' is a record is on } 190 \mathrm{~W} \text {, ' } 0 \text { ' } \\
\text { otherwise }\end{array}$ \\
\hline I290E & I290E & $\begin{array}{l}\text { Binary variable that is valued ' } 1 \text { ' is a record is on I290E, ' } 0 \text { ' } \\
\text { otherwise }\end{array}$ \\
\hline
\end{tabular}

Traffic and Weather Variables in the M odel for After-storm Performance

\begin{tabular}{|c|c|c|}
\hline $\begin{array}{l}\text { Total Snow } \\
\text { A ccumulation }\end{array}$ & TSA & $\begin{array}{l}\text { Total cumulative snowfall throughout the storm (liquid water } \\
\text { equivalent inches) }\end{array}$ \\
\hline Storm Duration & SD & Total storm duration (hours) \\
\hline Storm Intensity & SI & $\begin{array}{l}\text { intensity (Average hourly snow precipitation throughout the } \\
\text { storm) (inches/hour) }\end{array}$ \\
\hline \multirow{3}{*}{$\begin{array}{l}\text { M aximum Speed } \\
\text { Reduction Rate } \\
\text { Average Speed } \\
\text { Reduction Rate } \\
\text { M edian Speed } \\
\text { Reduction Rate }\end{array}$} & MXSRR & $\begin{array}{l}\text { Maximum hourly Speed Reduction Rate value in the snow event } \\
(\%)\end{array}$ \\
\hline & ASRR & $\begin{array}{l}\text { Average hourly Speed Reduction Rate value in the snow event } \\
(\%)\end{array}$ \\
\hline & MSRR & M edian hourly Speed Reduction Rate value in the snow event (\%) \\
\hline
\end{tabular}


Winter Highway Maintenance Operations

Table 2: Descriptive Statistics for During-storm Performance Analysis

\begin{tabular}{|c|c|c|c|c|c|c|}
\hline Segment & Variable & $\mathrm{N}$ & M inimum & M aximum & M ean & $\begin{array}{c}\text { Std. } \\
\text { Deviation }\end{array}$ \\
\hline \multirow{13}{*}{ I90E } & Speed Reduction Rate (\%) & 182 & -29.56 & 59.73 & 10.93 & 14.66 \\
\hline & Volume & 182 & 46 & 1369 & 456.97 & 299.26 \\
\hline & Volume Ratio & 182 & 0.1282 & 1.4327 & 0.8923 & 0.2133 \\
\hline & Precipitation (inches) & 182 & 0.0002 & 0.1241 & 0.0146 & 0.0247 \\
\hline & Accumulation (inches) & 182 & 0.0002 & 0.5451 & 0.0903 & 0.1333 \\
\hline & N th hour & 182 & 1 & 25 & 6.74 & 5.57 \\
\hline & Past Intensity (inches/hour) & 182 & 0 & 0.0580 & 0.0080 & 0.0111 \\
\hline & Storm Duration (hours) & 182 & 1 & 25 & 12.36 & 7.39 \\
\hline & Storm Intensity (inches/hour) & 182 & 0.0002 & 0.0335 & 0.0134 & 0.0100 \\
\hline & Precip(N-1) (inches) & 182 & 0 & 0.1241 & 0.0132 & 0.0252 \\
\hline & Precip(N-2) (inches) & 182 & 0 & 0.1241 & 0.0121 & 0.0249 \\
\hline & Precip(N-3) (inches) & 182 & 0 & 0.1241 & 0.0107 & 0.0245 \\
\hline & Precip(N-4) (inches) & 182 & 0 & 0.1241 & 0.0097 & 0.0235 \\
\hline \multirow{13}{*}{ I90W } & Speed Reduction Rate (\%) & 182 & -4.35 & 65.99 & 9.53 & 13.18 \\
\hline & Volume & 182 & 20 & 592 & 229.32 & 144.96 \\
\hline & Volume Ratio & 182 & 0.1366 & 1.4286 & 0.9103 & 0.2265 \\
\hline & Precipitation (inches) & 182 & 0.0002 & 0.1241 & 0.0146 & 0.0247 \\
\hline & Accumulation (inches) & 182 & 0.0002 & 0.5450 & 0.0903 & 0.1333 \\
\hline & $\mathrm{N}$ th hour & 182 & 1 & 25 & 6.74 & 5.57 \\
\hline & Past Intensity (inches/hour) & 182 & 0 & 0.0580 & 0.0080 & 0.0111 \\
\hline & Storm Duration (hours) & 182 & 1 & 25 & 12.36 & 7.39 \\
\hline & Storm Intensity (inches/hour) & 182 & 0.0002 & 0.0335 & 0.0134 & 0.0100 \\
\hline & Precip(N-1) (inches) & 182 & 0 & 0.1241 & 0.0132 & 0.0252 \\
\hline & Precip(N-2) (inches) & 182 & 0 & 0.1241 & 0.0121 & 0.0249 \\
\hline & Precip(N-3) (inches) & 182 & 0 & 0.1241 & 0.0107 & 0.0245 \\
\hline & Precip(N-4) (inches) & 182 & 0 & 0.1241 & 0.0097 & 0.0235 \\
\hline \multirow{13}{*}{$1290 \mathrm{E}$} & Speed Reduction Rate (\%) & 132 & -27.50 & 95.80 & 15.02 & 15.62 \\
\hline & Volume & 132 & 1 & 318 & 68.45 & 56.20 \\
\hline & Volume Ratio & 132 & 0.0000 & 3.0000 & 0.9586 & 0.5933 \\
\hline & Precipitation (inches) & 132 & 0.0004 & 0.1773 & 0.0174 & 0.0306 \\
\hline & Accumulation (inches) & 132 & 0.0004 & 0.5648 & 0.1098 & 0.1545 \\
\hline & $\mathrm{N}$ th hour & 132 & 1 & 25 & 6.20 & 5.66 \\
\hline & Past Intensity (inches/hour) & 132 & 0 & 0.1773 & 0.0143 & 0.0257 \\
\hline & Storm Duration (hours) & 132 & 1 & 25 & 11.54 & 7.86 \\
\hline & Storm Intensity (inches/hour) & 132 & 0.0004 & 0.0504 & 0.0159 & 0.0130 \\
\hline & Precip(N-1) (inches) & 132 & 0 & 0.1773 & 0.0148 & 0.0300 \\
\hline & Precip(N-2) (inches) & 132 & 0 & 0.1773 & 0.0138 & 0.0302 \\
\hline & Precip(N-3) (inches) & 132 & 0 & 0.1773 & 0.0127 & 0.0299 \\
\hline & Precip(N-4) (inches) & 132 & 0 & 0.1773 & 0.0116 & 0.0297 \\
\hline \multirow{13}{*}{ I290W } & Speed Reduction Rate (\%) & 133 & -4.03 & 76.07 & 14.79 & 15.63 \\
\hline & Volume & 133 & 2 & 491 & 184.26 & 122.54 \\
\hline & Volume Ratio & 133 & 0.0045 & 1.5455 & 0.8506 & 0.2562 \\
\hline & Precipitation (inches) & 133 & 0.0004 & 0.1773 & 0.0164 & 0.0289 \\
\hline & Accumulation (inches) & 133 & 0.0004 & 0.5648 & 0.1080 & 0.1538 \\
\hline & N th hour & 133 & 1 & 25 & 6.26 & 5.74 \\
\hline & Past Intensity (inches/hour) & 133 & 0 & 0.1773 & 0.0144 & 0.0258 \\
\hline & Storm Duration (hours) & 133 & 1 & 25 & 11.53 & 7.94 \\
\hline & Storm Intensity (inches/hour) & 133 & 0.0004 & 0.0504 & 0.0158 & 0.0129 \\
\hline & Precip(N-1) (inches) & 133 & 0 & 0.1773 & 0.0144 & 0.0299 \\
\hline & Precip(N-2) (inches) & 133 & 0 & 0.1773 & 0.0137 & 0.0301 \\
\hline & Precip(N-3) (inches) & 133 & 0 & 0.1773 & 0.0126 & 0.0298 \\
\hline & Precip(N-4) (inches) & 133 & 0 & 0.1773 & 0.0115 & 0.0296 \\
\hline
\end{tabular}


Winter Highway Maintenance Operations

Table 3: Descriptive Statistics for After-storm Speed Recovery Analysis

\begin{tabular}{|c|c|c|c|c|c|}
\hline Segment & V ariable & M inimum & Maximum & M ean & $\begin{array}{c}\text { Std. } \\
\text { Deviation }\end{array}$ \\
\hline \multirow{9}{*}{ I90E } & Storm Duration & 2 & 25 & 10.06 & 6.20 \\
\hline & Total Snow A ccumulation & 0.0020 & 0.5450 & 0.1421 & 0.1652 \\
\hline & Storm Intensity & 0.0010 & 0.0484 & 0.0144 & 0.0135 \\
\hline & M aximum Speed Reduction (\%) & 1.39 & 59.73 & 24.729 & 15.490 \\
\hline & A verage Speed Reduction (\%) & 0.5929 & 25.2065 & 10.8506 & 7.3682 \\
\hline & M edian Speed Reduction (\%) & 0.69 & 28.25 & 10.487 & 8.4644 \\
\hline & Speed Recovery Duration 1 & 0 & 37 & 5.89 & 9.07 \\
\hline & Speed Recovery Duration 2 & 0 & 12 & 2.39 & 3.68 \\
\hline & AVGSRD & 0.25 & 17.25 & 4.4583 & 4.4161 \\
\hline \multirow{9}{*}{ I90W } & Storm Duration & 2 & 25 & 10.89 & 5.97 \\
\hline & Total Snow A ccumulation & 0.0028 & 0.5450 & 0.1474 & 0.1620 \\
\hline & Storm Intensity & 0.0010 & 0.0363 & 0.0153 & 0.012 \\
\hline & M aximum Speed Reduction (\%) & 1.78 & 65.99 & 21.8783 & 17.2921 \\
\hline & A verage Speed Reduction (\%) & 1.4350 & 25.3759 & 9.1341 & 7.3160 \\
\hline & M edian Speed Reduction (\%) & -0.37 & 26.10 & 8.2367 & 8.2110 \\
\hline & Speed Recovery Duration 1 & 0 & 24 & 5.67 & 6.13 \\
\hline & Speed Recovery Duration 2 & 0 & 12 & 1.22 & 3.06 \\
\hline & $A \vee G S R D$ & 0.00 & 10.75 & 3.3611 & 3.4855 \\
\hline \multirow{9}{*}{ I290E } & Storm Duration & 6 & 22 & 12.23 & 5.04 \\
\hline & Total Snow A ccumulation & 0.0107 & 0.5648 & 0.17951 & 0.1612 \\
\hline & Storm Intensity & 0.0015 & 0.0550 & 1.9891 & 0.0143 \\
\hline & M aximum Speed Reduction (\%) & 16.07 & 95.84 & 37.749 & 19.6079 \\
\hline & A verage Speed Reduction (\%) & 3.8437 & 21.6082 & 15.1816 & 6.2688 \\
\hline & M edian Speed Reduction (\%) & 1.74 & 23.85 & 13.7262 & 8.0440 \\
\hline & Speed Recovery Duration 1 & 0 & 17 & 5.69 & 5.14 \\
\hline & Speed Recovery Duration 2 & 0 & 13 & 1.92 & 3.95 \\
\hline & AV GSRD & 0.00 & 11.00 & 2.7885 & 2.7154 \\
\hline \multirow{9}{*}{ I290W } & Storm Duration & 6 & 22 & 12.36 & 5.24 \\
\hline & Total Snow A ccumulation & 0.0107 & 0.5648 & 0.1966 & 0.1699 \\
\hline & Storm Intensity & 0.0015 & 0.0550 & 0.0205 & 0.0155 \\
\hline & M aximum Speed Reduction (\%) & 3.62 & 76.07 & 30.629 & 18.449 \\
\hline & A verage Speed Reduction (\%) & 0.9971 & 33.4311 & 15.982 & 9.9144 \\
\hline & M edian Speed Reduction (\%) & 1.68 & 31.37 & 14.723 & 10.5654 \\
\hline & Speed Recovery Duration 1 & 0 & 29 & 10.73 & 9.85 \\
\hline & Speed Recovery Duration 2 & 0 & 14 & 2.64 & 4.46 \\
\hline & AVGSRD & 0.25 & 21.00 & 5.8409 & 5.6913 \\
\hline
\end{tabular}




\section{ESTIMATION AND RESULTS}

Using the data just described, the following linear model is estimated via the two-step procedure outlined in the methodology section:

(1) $\operatorname{SRR} \quad \alpha_{0}+\sum_{i} \alpha_{i} X_{i}+\sum_{j} \beta_{j} Z_{j}+\sum_{i} \sum_{j} \gamma_{i j} X_{i} Z_{j}$

Where $S R R$ is the speed reduction rate, $X_{i} \in(V, V R, P, A, N H, P I, S D, S I, P N I, P N 2, P N 3, P N 4)$ and, $Z_{i} \in(I 90 E, I 90 W, I 290 E)$ the variables are already defined in Table 1 and $\alpha, \beta$, and $\gamma$ are the coefficients to be estimated.

The results of the estimation are reported in Table 4. Here, only the predictors whose parameters are statistically significant at the 0.10 level are shown. A Durbin-Watson test reveals no serial autocorrelation in the dependent variables, while the test statistics detect no collinearity. The coefficient of determination of the estimated model is 0.354 with an F statistic of 19.676, which is statistically significant at the 0.0001 level. The results show that only five of the variables listed in Table 1 or their interactions with the instrumental variables describing traffic direction and jurisdiction have statistically significant impacts on the speed reduction rate. They are accumulation (A), precipitation in the current hour (P), the previous hour's precipitation (PN1), volume ratio, and storm duration. The estimation also identifies several significant variables tied to the instrumental dummies I90W, I90E, and I290E, including accumulation and the previous hour's precipitation. They are the indicators $\mathrm{I} 90 \mathrm{E}$ and $\mathrm{I} 90 \mathrm{~W}$, and their respective interactions with cumulative snowfall since the start of the storm and the previous hour's precipitation, i.e., (I90E * A) and (I90W * PN1). The coefficients of I90E and I90W are negative, their values being -5.571 and -5.742 . These coefficients correspond to the differences in the intercepts for the segments $\mathrm{I} 90 \mathrm{E}$, and $\mathrm{I} 90 \mathrm{~W}$ to segment $1290 \mathrm{~W}$. Another interesting result is that the coefficients of the interaction terms involving I90E and accumulation, and I90 W and precipitation during the previous hour are positive and significant and greater than the coefficients of accumulation and precipitation. Therefore, the I90 segments lose speed faster than the I290 segments as weather conditions worsen, i.e., with greater snow accumulation on the pavement and or higher precipitation during the previous hour.

Table 4: Results of the Model of During-storm Maintenance Performance

\begin{tabular}{cccccc}
\hline Variable & $\begin{array}{c}\text { Non-standardized } \\
\text { Coefficient }\end{array}$ & Std. Error & $\begin{array}{c}\text { Standardized } \\
\text { Coefficient }\end{array}$ & T Statistic & Sig. \\
\hline (Constant) & 15.637 & 1.936 & & 8.076 & 0.000 \\
I90W & -5.742 & 1.305 & -0.176 & -4.399 & 0.000 \\
I90E & -5.571 & 1.395 & -0.171 & -3.994 & 0.000 \\
A & 23.273 & 4.663 & 0.223 & 4.991 & 0.000 \\
P & 128.702 & 21.581 & 0.234 & 5.964 & 0.000 \\
PN1 & 43.059 & 25.031 & 0.079 & 1.720 & 0.086 \\
VR & -4.775 & 1.522 & -0.110 & -3.137 & 0.002 \\
SD & -0.151 & 0.067 & -0.078 & -2.257 & 0.024 \\
I90E * A & 27.192 & 8.012 & 0.151 & 3.394 & 0.001 \\
I90W * PN1 & 99.507 & 42.197 & 0.099 & 2.358 & 0.019 \\
\hline
\end{tabular}


The analysis of the variables tied to the instrumental dummies I90W, I90E, and I290E sheds new light on the implications of differential roadway maintenance standards on mobility performance during snow events. The constants specific to the 190 segments are statistically significant and quite large, while the intercept for $\mathrm{I} 290 \mathrm{E}$ is not even significant. After controlling for weather and traffic conditions, most notably accumulation, precipitation, precipitation during the previous hour, volume ratio, and storm duration, the NYSTA facilities show significantly higher mobility performance during snow events than the facilities maintained by NYSDOT. More specifically, an examination of the non-standardized regression coefficients indicates that speed on the studied segments of I90 is $5.571 \%$ to $5.742 \%$ lower than on comparable segments of I290. Furthermore, the positive coefficients of the products of the I90 dummies, accumulation and the previous hour's precipitation show that the discrepancy in speed reduction rates on NYSTA and NYSDOT facilities shrinks with greater snow accumulation or at a later stage of the storm. Thus, in much harsher circumstances, NYSTA is not able to maintain its mobility advantage in spite of greater amount of resources it devotes to winter maintenance operations. To summarize, the levels of service of the two facilities exhibit systematic and observable differences, most notably in the early stage of storms and during small storm events.

\section{Results of the After-storm Speed Recovery Model}

Multiple linear regression models are estimated to establish the quantitative relationship between three possible formulations of speed recovery and the independent variables listed above. The average of full and 95\% speed recovery time (AVGSRD) has the highest goodness-of-fit so only its results are reported here. In Table 5, the stepwise variable selection process retains two significant variables, namely the median speed reduction rate and storm duration, and the results test negatively for serial autocorrelation, heteroscedasticity, and collinearity. The R-square is 0.342 , while the F statistic is 14.784 , which is significant at 0.0001 . Not surprisingly, speed recovery is slower for longer storms and for storms marked by greater median speed reduction. More importantly though, none of the instrumental variables for the interstate highways $190 \mathrm{E}, 190 \mathrm{~W}$, and $\mathrm{I} 290 \mathrm{E}$ is found to be statistically significant at the 0.10 level, whether on their own or interactively with other weather or traffic variables. Therefore, there is no statistical evidence to support the hypothesis that after-storm mobility performances of the two facilities are different once the analysis controls for median speed reduction during the storm and storm duration.

Table 5: Estimation of Speed Recovery Duration Model (AVGSRD Dependent Variable)

\begin{tabular}{cccccc}
\hline V ariable & $\begin{array}{c}\text { Non- } \\
\text { standardized } \\
\text { Coefficient }\end{array}$ & Std. Error & $\begin{array}{c}\text { Standardized } \\
\text { Coefficient }\end{array}$ & T Stat. & Sig. \\
\hline $\begin{array}{c}\text { (Constant) } \\
\text { M edian Speed Reduction } \\
\text { Rate }\end{array}$ & -0.904 & 1.096 & & -0.825 & 0.413 \\
$\begin{array}{c}\text { Storm Duration } \\
\text { Ston }\end{array}$ & 0.222 & 0.051 & 0.474 & 4.385 & 0.000 \\
\hline
\end{tabular}

\section{CONCLUSIONS AND RECOMMENDATIONS}

Winter storms have a profound, negative impact on mobility in the Buffalo metropolitan area as well as in many other cities of the United States. The controlled access highway network in this area consists of two parts, one maintained by the New York State Department of Transportation and the other by the New York State Thruway Authority. These agencies have differing response standards for snow and ice control activities for the same highway classification. The purpose of this 
study was to identify discrepancies in mobility performance during the winter season between the highways maintained by NYSTA and NYSDOT. Mobility performance was evaluated in terms of speed reduction during snow events and speed recovery duration following the end of snow events.

The statistical analysis shows that the average loss of speed is about $5.6 \%$ to $5.7 \%$ higher on I290 segments than on I90 segments during snow events. The stepwise regression model identified important predictors of speed rate reduction. They are the current hourly precipitation, accumulation, the previous hour's precipitation, volume ratio, and storm duration. Even after statistically controlling for weather and traffic conditions, NYSTA facilities exhibit significantly higher mobility performance than facilities maintained by NYSDOT during snow events. In addition, the discrepancy in speed reduction rates on NYSTA and NYSDOT facilities tends to shrink with greater snow accumulation on the highway pavement or at a later stage of the storm. As weather conditions worsen, NYSTA seems to face an increasingly insurmountable challenge as it struggles to maintain its mobility advantage by applying greater resources to winter maintenance operations. Mobility on NYSTA and NYSDOT facilities exhibits systematic differences during snow events, most notably in the early stages of storms and during small events.

The analysis shows that after-storm performance is primarily tied to median hourly speed reduction and storm duration. Interestingly, no significant difference was detected in after-storm performance between NYSTA and NYSDOT facilities. While further analysis of the complexity of the relationship between during-storm speed reduction, intensity, or duration of the storm, and winter maintenance practices is warranted, the following recommendations can be made on the basis of the statistical results on hand. Any supplemental resource dedicated by NYSDOT for ice control and snow removal should be targeted to the onset of snowstorms when a greater impact can be realized, or even before precipitation starts. Specifically, implementing more effective anti-icing activities would be an appropriate strategy. ${ }^{6}$ Although NYSDOT has adopted an anti-icing strategy using pre-wetted solid chemicals, the statistical analysis of during-storm roadway performance reveals that this strategy is not sufficient. In the future, anti-icing experiments should be carried out to support the above recommendation.

Finally, the fact that NYSTA facilities perform statistically no better that NYSDOT facilities after a snow event and NYSTA's mobility advantage fades during long and intense storms puts into question the economic rationale of NYSTA's resource-intensive winter maintenance operations. An analysis is advised to assess the cost-effectiveness of investments aimed at maintaining the mobility performance of NYSTA's facilities during the winter season.

\section{Endnotes}

1. For more details on scientific and engineering aspects of NEXRAD, see Crum and Alberty (1993), and Crum et al. (1998), and Brown and Baass (2005).

2. www ncdc noaa.gov/nexradinv

3. For convenience a snowstorm event is defined as it is in the NEXRAD dataset.

4. The accident data could be analyzed to compare safety performance of highways in storm events under different winter maintenance regimes. However, this is outside the scope of this paper since it aims to propose a simple, user-oriented index of mobility performance of winter maintenance operations.

5. Snowfall in the study area varies quite substantially with location as a result of the so-called "lake effect." 
Winter Highway Maintenance Operations

6. Roadway anti-icing is a snow and ice control strategy for preventing the formation or development of bonded snow and ice to a pavement surface by timely applications of a chemical freezing-point depressant (Boselly 2001).

\section{References}

Adams, T.M., M. Danijarsa, T. Martinelli, G. Stanuch, and A. Vonderohe. "Performance Measures for Winter Operations." Transportation Research Record 1824, (2003): 87-97.

Blackburn, R.R., K.M. Bauer, D.E. Amsler, S.E. Boselly, and A.D. McElroy. Snow and Ice Control: Guidelines for Materials and Methods. NCHRP Report 526, Transportation Research Board, Washington, D.C., 2004.

Boselly, S.E. Benefit/Cost Study of RWIS and Anti-icing Technologies. NCHRP Report 20-7 (117), Transportation Research Board, Washington, D.C., 2001.

Botha, J.L. and T.R. Kruse. "Flow Rates at Signalized Intersections under Cold Winter Conditions." Journal of Transportation Engineering 118(3), (1992): 439-451.

Brown, B. and K. Baass. "Seasonal Variation in Frequencies and Rates of Highway Accidents as a Function of Severity." Transportation Research Record 1581, (1997): 59-65.

Brown, R.A. and J.M. Lewis. "Path to NEXRAD: Doppler Radar Development at the National Severe Storms Laboratory." Bulletin of the American Meteorological Society 86(10), (2005): 14591470.

Crum, T. and R. Alberty. "The WSR-88D and the WSR-88D Operational Support Facility." Bulletin of the American Meteorological Society 74(9), (1993): 1669-1687.

Crum, T.D., R.E. Saffle, and J.W. Wilson. "An Update on the NEXRAD Program and Future WSR88D Support to Operations.” Weather and Forecasting 13(2), (1998): 253-262.

Decker, R., J.L., Bignell, C.M., Lambertson and K.L. Porter. "Measuring Efficiency of Winter Maintenance Practices.” Transportation Research Record 1741, (2004): 167-175.

Fulton, B.A. WSR-88D Polar-to-HRAP Mapping. Technical Memorandum of Hydrologic Research Laboratory, Office of Hydrology, National Weather Service, Silver Spring, MD, 1998.

Hall, F.L. and D. Barrow. "Effect of Weather on the Relationship between Flow and Occupancy on Freeways." Transportation Research Record 1194, (1988): 55-63.

Hanbali, R.M. "Economic Impact of Winter Road Maintenance on Road Users." Transportation Research Record 1442, (1994): 151-161.

Hanbali, R.M. and D.A. Kuemmel. "Traffic Volume Reductions Due to Winter Storm Conditions." Transportation Research Record 1387, (1993): 159-164.

Ibrahim, A.T. and F.L. Hall. "Effect of Adverse Weather Conditions on Speed-Flow-Occupancy Relationships." Transportation Research Record 1457, (1994): 184-191.

Klazura, G.E. and D.A. Imy. "A Description of the Initial Set of Analysis Products Available from the NEXRAD WSR-88D System." Bulletin of the American Meteorological Society 74(7), (1993): 1293-1311. 
Knapp, K.K., D. Kroeger, and K. Giese. Mobility and Safety Impacts of Winter Storm Events in a Freeway Environment. Final Report. CTRE Management Project 98-39, Center for Transportation Research and Education, Iowa State University, Ames, IA, $2000 \mathrm{~b}$.

Knapp, K.K. and L.D. Smithson. "Winter Storm Event Volume Impact Analysis Using MultipleSource Archived Monitoring Data.” Transportation Research Record 1700, (2000): 10-16.

Knapp, K.K., L.D. Smithson, and A.J. Khattak. "The Mobility and Safety Impacts of Winter Storm Events in a Freeway Environment." Mid-Continent Transportation Symposium 2000 Proceedings, Center for Transportation Research and Education, Iowa State University, Ames, IA, (2000a): 6771.

Kyte, M., Z. Khatib, P. Shanon, and F. Kitchener. "Effect of Weather on Free-Flow Speed." Transportation Research Record 1776, (2001): 60-68.

Lee, C. and B. Ran. "Pilot Study to Measure the Potential of Using Speed Recovery Duration as a Winter Maintenance Performance Measure." Transportation Research Record 1877, (2004): 137 143.

Liang, W.L., M. Kyte, F. Kitchener, and P. Shannon. "Effect of Environmental Factors on Driver Speed." Transportation Research Record 1635, (1998): 155-161.

Marshall, K. R. “TRANSMIT, An Advanced Traffic Management System.” PB Network, (1997): 20-23.

McBride, J.C. "Economic Impact of Highway Snow and Ice Control." Transportation Research Record 678, (1978): 58-63.

NCDC. NCDC NEXRAD Data Inventory Search. www ncdc noaa.gov/nexradinv, 2008, accessed November 23, 2008.

Niver, E., K.C. Mouskos, T. Batz, and P. Dwyer. "Evaluation of the TRANSCOM's System for Managing Incidents and Traffic (TRANSMIT)." IEEE Transactions on Intelligent Transportation Systems 1 (1), (2000): 15-31.

Nixon, W. The Potential of Friction as a Tool for Winter Maintenance. Iowa Institute of Hydraulic Research Report No. 392, College of Engineering, University of Iowa, Iowa City, IA, 2008.

Niziol, T.A., W.R. Snyder, and J.S. Waldstreicher. "Winter Weather Forecasting Throughout the Eastern United States. Part IV: Lake Effect Snow.” Weather and Forecasting 10, (1995): 61-70.

NWS. Snowfall - Average Total in Inches. National Weather Service. http://lwf ncdc.noaa.gov/oa/ climate/online/ccd/snowfall.html, 2004, accessed May 23, 2008.

Padget, E.D., K.K. Knapp, and G.B. Thomas. "Investigation of Winter-weather Speed Variability in Sport Utility Vehicles, Pickup Trucks, and Passengers Cars." Transportation Research Record 1779, (2001): 116-124.

Perry, A.H., and L.J. Symons. Highway Meteorology. University College of Wales, Swansea, United Kingdom, 1991.

Ries, G.L. Impact of Weather on Freeway Capacity. Minnesota Department of Transportation, Office of Traffic Engineering, Systems and Research Section, Minneapolis, MN, 1981. 
Stern, A.D., F. Church, V. Shah, L. Goodwin, and J. Pisano. "Analysis of Weather Impacts on Traffic Flow in Metropolitan Washington, D.C." Proceedings of the Meeting on Interactive Information and Processing Systems, American Meteorology Society, Boston, MA, http://ops fhwa.dot.gov/ weather/best_practices/AMS2003_TrafficFlow.pdf, 2003, accessed May 20, 2007.

Sun, H. and J.C. Thill. "The Reliability of Traffic Volume Estimation Using TRANSMIT." Paper presented at the Annual Meetings of the Association of American Geographers, Chicago, IL, 2006.

Vaa, T. "Methods for Measuring and Reporting Winter Maintenance Activities." Transportation Research Record, 1741, (2001): 152-158.

Yamada, T., A. Sugimura, and T. Maruyama. "Research on the Level of Winter Road Management." Transportation Research E-Circular Number E-C063, Sixth International Symposium on Snow Removal and Ice Control Technology, Transportation Research Board, Washington, D.C., 139-152, 2004.

\section{Acknowledgements}

The authors thank the engineers, scientists, and staff of NITTEC, and of the Buffalo offices of NYSDOT, NYSTA, and NWS for their support in data collection and valuable advice during the conduct of this research. The content of this paper reflects the views of the authors only. Dr. Obeng's careful editing helped to clarify some of the arguments made in the paper.

Jean-Claude Thill is the Knight Distinguished Professor of Public Policy, Department of Geography \& Earth Sciences, at the University of North Carolina in Charlotte. He has published extensively on various aspects of transportation systems, particularly regarding regional economic impacts, accessibility, safety, hazmat routing, and Geographic Information Systems. His work has appeared in Transportation Research B, Transportation Research C, Transportation Research Record, Transportation Planning and Technology, Environment and Planning A and B, Journal of Transport Geography, and various regional science and geography journals. He presently is editor-in-chief of Computers, Environment and Urban Systems.

Hai Sun is presently at the Department of Geography, The State University of New York at Buffalo, Wilkeson Quad, Amherst, NY. He holds a master's degree in geography from the State University of New York at Buffalo and a business degree from the People's Republic of China. His interests include the modeling of transportation systems and spatial modeling. 